https://doi.org/10.47370/2078-1024-2021-13-3-29-47

УДК 791/796(09)(470.67)

Каймаразов Г.Ш., Каймаразова Л.Г.

ДАГЕСТАНКА В СИСТЕМЕ ФИЗИЧЕСКОЙ КУЛЬТУРЫ И СПОРТА В 1930-Е ГГ.: ИСТОРИЧЕСКИЙ АСПЕКТ ТРАНСФОРМАЦИИ ГЕНДЕРНЫХ СТЕРЕОТИПОВ

\author{
Каймаразов Гани Шихвалиевич, \\ доктор исторических наук, профессор, главный научный сотрудник отде- \\ ла новой и новейией истории Дагестана Института истории, археологии \\ и этнографии Дагестанского федөрального исследовательского иентра \\ Российской академии наук, Махачкала, Россия, \\ тел.: +7 (928) 9412806

\section{Каймаразова Лейла Ганиевна,} \\ кандидат исторических наук, ведуций научный сотрудник отдела новой и \\ новеймей истории Дагестана Института истории, археологии и этногра- \\ фии Дагестанского федерального исследовательского чентра Российской \\ академии наук, Махачкала, Россия, \\ e-mail: kaymarazova@mail.ru, \\ тел.: +7 (928) 9412806
}

\begin{abstract}
Аннотация
Актуальность исследования определяется научным и практическим интересом к истории отечественной физической культуры и спорта, политике государства в этой сфере, в том числе в национальных районах страны в раннесоветский период, а также развернувшимися в наши дни в мировом сообществе дискуссиями о судьбах женского спорта. В статье впервые на основе достоверного фактического материала, с учетом современных историографических обобщений проанализированы трансформации, происходившие в 1930-е гг. в структуре женской гендерной роли на примере участия в физкультурном движении и спорте женщин многонационального Дагестана, которое становилось все более заметным, несмотря на сохранение значительного влияния ислама и традиционных представлений о месте женщины в системе общественных отношений и семье.

Исследование, выполненное в рамках социокультурной, гендерной истории, истории повседневности на основе принципов историзма и объективности с применением сравнительно-исторического, проблемно-хронологического, описательного методов и учетом основных положений модернизационной концепции, позволило прийти к выводам о том, что в 1930-е гг. руководство респуболики и региона сталло уделять приоритетное внимание вовлечению девушек-горянок в физкультурное и военно-спортивное движение, которое стало одной из составляющих программы решения «женского вопроса», осуществление которого позволило всё активнее привлекать дагестанок к участию в общественно-политической и культурной жизни республики, края, страны.
\end{abstract}


Ключевые слова: физическая культура, спорт, спартакиада, военно-спортивное движение, Дагестан, женщина-горянка, ислам, традиционные представления, гендерные стереотипы, гендерные роли

Дия циитирования: Каймаразов Г.Ш., Каймаразова Л.Г. Дагестанка в системе физической культуры и спорта в 1930-е гг.: исторический аспект трансформачии гендерных стереотипов // Вестиик Майкопского государственного технологического универcumema. 2021. Tом 13, № 3. C. 29-47. https:/doi.org/10.47370/2078-1024-2021-13-3-29-47.

Kaymarazov G.Sh., Kaymarazova L.G.

\title{
A DAGESTIANI WOMAN IN THE SYSTEM OF PHYSICAL CULTURE AND SPORT IN 1930S: A HISTORICAL ASPECT OF THE GENDER STEREOTYPES TRANSFORMATION
}

\author{
Kaymarazov Ganih Shikhvalievich, \\ Doctor of History, a professor, a chief researcher of the Department of Modern \\ and Contemporary History of Dagestan, Institute of History, Archeology and \\ Ethnography of the Dagestan Federal Research Center of the Russian Academy \\ of Sciences, Makhachkala, Russia, \\ tel.: +7. (928) 9412806 \\ Kaymarazova Leyla Ganhievna, \\ Candidate of History, a leading researcher of the Department of Modern and \\ Contemporary History of Dagestan, Institute of History, Archeology and Eth- \\ nography of the Dagestan Federal Research Center of the Russian Academy \\ of Sciences, Makhachkala, Russia, \\ e-mail: kaymarazova@mail.ru, \\ tel.: +7. (928) 9412806
}

\section{Annotation}

The relevance of the study is determined by the scientific and practical interest in the history of national physical culture and sports, the state policy in this area, including in the national regions of the country in the early Soviet period, as well as the discussions that have unfolded in the world community today about the fate of women's sports. For the first time, the article analyzes the transformations that took place in the 1930s on the basis of reliable factual materials, taking into account modern historiographic generalizations in the structure of women's gender role on the example of participation in the physical culture movement and sports of women of multinational Dagestan, which became more and more noticeable, despite the preservation of the significant influence of Islam and traditional ideas about the place of women in the system of social relations and the family.

The research carried out within the framework of socio-cultural, gender history, the history of everyday life on the basis of the principles of historicism and objectivity with the use of comparative-historical, problem-chronological, descriptive methods and taking into account the main provisions of the modernization concept, led to the conclusion that in the $1930 \mathrm{~s} . .$. the leadership of the republic and the region began to give priority attention to the involvement of mountain girls in the physical culture and military-sports movement, which became one of the components of the program for solving the "women's issue", the implementation of which made it possible to more and more 
actively attract Dagestani women to participate in the socio-political and cultural life of the republic, edges, countries.

Keywords: physical culture, sports, sports days, military sports movement, Dagestan, mountain woman, Islam, traditional ideas, gender stereotypes, gender roles

For citation: Kaymarazov G.Sh., Kaymarazova L.G. A Dagestiani woman in the system of:physical culture and sport in 1930s: a historical aspect of the gender stereotypes transformation // Vestnik Majkopskogo gosudarstvennogo tehnologiceskogo universiteta. 2021. Volume 13, No. 3. P. 29-47. https:/doi.org/10.47370/2078-1024-2021-13-3-29-47.

Актуальность нашего исследования в первую очередь обусловлена неослабевающим интересом, как научным, так и практическим, к истории отечественного спорта. Тем более, политика государства в сфере физической культуры и спорта сегодня нацелена на создание необходимых условий для ее поступательного развития, на формирование культуры и ценностей здорового образа жизни населения страны [37]. Нам представляется, что тему исследования актуализируют и развернувшиеся в мировом сообществе дискуссии о судьбах женского спорта в условиях, когда усилившееся распространение известного социального тренда на профессиональный спорт грозит лишить девушек шансов достигнуть победных высот в соревнованиях с мужчинами.

Особое место в летописи развития физической культуры и спорта России занимают страницы региональной истории. Яркими и неординарными фактами отмечено повествование о советском опыте реализации государственной политики в обозначенной области в многонациональном Дагестане. Авторы статьи впервые обращаются к трансформациям, происходившим в 1930-е гг. в структуре женской гендерной роли, на примере участия в физкультурном движении женщин Дагестана. Это участие становилось все более заметным, несмотря на сохранение в дагестанском обществе значительного влияния ислама и традиционных представлений о месте женщины в системе общественных отношений и семье.
Настоящее исследование проведено в рамках социокультурной, гендерной истории, истории повседневности. Цель работы - рассмотреть процесс вовлечения женщин Дагестана, в частности горянок, в занятия физической культурой и спортом, и что особенно важно, посредством этого - в общественно-политическую и социально-культурную жизнь республики, региона, страны. Выбор хронологических рамок - 1930-е гг. - не случаен. Они охватывают период от времени «Великого перелома» (рубеж 19201930-х гг.), когда физкультура стала одним из инструментов мобилизации населения [46, с. 798], до конца 1930-х гг., когда наступил период крайней нестабильности международной обстановки, стали происходить вооруженные конфликты с прямым или косвенным участием Советского Союза, и со всей неотвратимостью проступали очертания предстоящей войны, потребовавшей от народов всей страны неимоверного напряжения сил как физических, так и моральных.

Географические рамки исследования определены современной территорией Республики Дагестан.

Обозначенная научная проблема ранее не являлась объектом специального исследования не только в северокавказском регионе, но и в других районах страны [27, с. 150]. Правда, в отдельных работах, в том числе посвященных истории культуры, а также физической культуры и спорта, приводятся эпизодические сведения о занятиях женщин спортом и их достижениях в этой области $[18 ; 22 ; 40$; 
43]. Из российских авторов, уделивших внимание интересующей нас проблеме, заслуживают быть отмеченными исследования М.И. Мирошниченко [28].

Научных публикаций о развитии физкультуры и спорта в Дагестане немного. Несколько работ известных спортсменов республики и специалистов в этой области увидели свет в 1960-1970-е годы. В 1966 г. Дагестанское учебно-педагогическое издательство выпустило небольшую по объему книгу доцента Дагестанского педагогического института Ф.А. Агапова «Очерки развития физической культуры в Дагестане» [2]. Двумя годами ранее его очерки о развитии физкультуры и спорта в Северной Осетии вышли в Opджоникидзе [4]. В 1971 г. издательство «Дагучпедгиз» опубликовало новый научный труд Ф.А. Агапова «Физическая культура и спорт у горских народов Северного Кавказа» [3]. В 1972 г. в Дагестанском книжном издательстве увидела свет богато иллюстрированная монография известного спортсмена и наставника спортивной молодежи М.-Ш. Ахмедова «Знаменосцы дагестанского спорта» [6], в которой были собраны биографии выдающихся и широко известных в республике, стране и за ее пределами дагестанских спортсменов. В 1975 г. совместная работа Ф.А. Агапова и М.-Ш. Шарипова увенчалась изданием небольшой, но содержащей новые и интересные специалистам и широкой читательской аудитории книги «ГТО на службе здоровья» [5]. Одним из первых в свои научные монографии по истории культуры народов Дагестана и Северного Кавказа сюжеты о развитии в регионе физической культуры и спорта стал вводить Г.Ш. Каймаразов [19; 20]. Названными авторами был собран и вовлечен в научный оборот обширный фактический материал по проблеме в целом, сделаны ценные научные обобщения. И хотя в них присутствуют сведения об участии дагестанок в физкультурном движении, в спортивных кружках и обществах, отражены их достижения в спортивных состязаниях, интересующий нас аспект последовательного освещения не получил.

Зарубежные авторы также не обошли вниманием тему развития физической культуры и спорта в СССР в раннесоветский период. Их в частности интересовало, как в эти годы происходил процесс складывания милитаризованной модели культурного поведения советской молодежи [7], формирование которой напрямую зависело от овладения юношами и девушками военно-оборонными навыками и достижения ими совершенной физической формы.

Источниковую базу нашего исследования составили документы Центрального государственного архива Республики Дагестан (ЦГА РД), в частности материалы фондов Совета министров Республики Дагестан (168-p) и Дагестанского совета физической культуры и спорта (187-p), а также данные периодических изданий, главным образом газеты «Дагестанская правда» (до 1932 г. - «Красный Дагестан»). К слову, в периодической печати спортивные события, происходящие в стране, регионе и республике, получают систематическое освещение именно с начала рассматриваемого десятилетия.

Несмотря на то что сегодня идет качественное переосмысление многих теоретических и методологических установок отечественной исторической науки, методологической основой нашего исследования остались принципы историзма и объективности. Выстроить сюжет статьи на базе собранного нами фактического материала на избранном историческом отрезке времени, связать региональные особенности с общероссийскими закономерностями и синхронизировать их с общемировыми событиями помогли историко-сравнительный, проблемно-хронологический, историко-типологический методы. Наше внимание привлекла и набирающая на 
сегодняшний день популярность модернизационная концепция как способ изучения истории государства и общества с учетом внутренних и внешних факторов, установления преемственности исторических явлений и определения перспектив развития [17, с. 397]. Авторами также широко применялись описательный и биографический методы.

В статье использовались определения, содержание которых отвечает их современной трактовке в соответствии с законодательством Российской Федерации $[37 ; 45]$.

Физическая культура - часть культуры как совокупность ценностей и знаний для физического и интеллектуального развития способностей человека, формирования здорового образа жизни.

Спорт - сфера социально-культурной деятельности как совокупность видов спорта, сложившаяся в форме соревнований и специальной практики подготовки к ним, направленная на получение максимального результата и спортивных наград.

Массовый спорт - часть спорта, ориентированная на физическое воспитание и физическое развитие граждан посредством проведения организованных и самостоятельных занятий, а также участия в физкультурных мероприятиях. В основе «массовости физической культуры» лежат социальные потребности в физическом совершенствовании людей, в их оздоровлении, организации досуга. Массовость физической культуры в раннесоветский период получила закрепление в лозунге, выдвинутом председателем Высшего Совета физической культуры Н.И. Подвойским: «Физическую культуру - в массы!». Для определения критерия «массовости» спорта мы прибегли к мнению историков физической культуры и спорта, в частности М.И. Золотова, который посчитал, что для выполнения спортом всех своих функций - социальной, экономической, оздоровительной и пр. (в этот список мы бы в обязательном порядке добавили социально-культурную - прим. авт.) - необходимо, чтобы спортом регулярно занималось $30 \%$ населения $[40$, с. 66$]$

Национальные виды спорта - исторически сложившиеся в этнических группах населения виды спорта, имеющие социально-культурную направленность.

Физкультурно-спортивное общество - организация, осуществляющая развитие физической культуры и спорта по отраслевому принципу принадлежности к профессии.

Физкультурно-оздоровительный комплекс «Готов к труду и обороне» (ГТО) - программная и нормативная основа системы физического воспитания населения, устанавливающая государственные требования к уровню его физической подготовленности.

Гендерные стереотипы - распространенные в обществе представления об особенностях и поведении мужчин и женщин, в нашем случае рассматриваемые как представления о распределении социальных ролей между ними. K пониманию особенностей гендерных стереотипов в дагестанском обществе можно приблизиться, учитывая его экономическое, политическое, социальное пространство, через изучение его культурной специфики (национальной, традиционной, духовной, бытовой).

И, наконец, гендерные особенности в спорте - определение, в раскрытии содержания которого должны учитываться и физический, и психологический, и традиционный, и культурный аспекты. Исторически спорт был исключительно мужским делом, в частности в силу физической выносливости мужского организма. Только в 1924 г. женщины добились права участвовать в Олимпийских играх и постепенно стали заниматься видами спорта, которые прежде считались чисто мужскими. В то же время физиологические особенности мужского 
и женского организма - разное строение мускулатуры и скелета, отличия в размере сердца и жизненном объеме легких и др. - обусловили раздельные соревнования мужчин и женщин во всех спортивных дисциплинах, кроме конного спорта. Помимо этого, мужчины больше, чем женщины подвержены гендерным стереотипам, у них лучше развита логика мышления, меньше - личностная тревожность и конфликтность. Они больше ориентированы на успех в спорте, нежели женщины. Женщин отличает высокая самооценка, эмоциональность и эмпатия (осознанное сопереживание эмоциональному состоянию другого человека и выражение сострадания). Эти психологические характеристики довольно отчетливо проступали при анализе оказавшихся в нашем распоряжении источников.

В Дагестане издавна сложились свои национальные виды спорта и спортивные традиции, обусловленные тягой дагестанцев к физическим упражнениям, играм, песням и пляскам. У народов горного края были популярны метание камня с помощью пращи, метание копья, стрельба из ружья и пистолета, ценилось искусное владение арканом, кинжалом, мечом, секирой, булавой, практиковались скачки и джигитовка, борьба, хождение по канату и на ходулях, развивались акробатика, катание на коньках, фехтование на шашках, поединки с кинжалами. Со временем возникли парусное и гребное дело, народный туризм и альпинизм [3, с. 68]. Эти спортивные традиции народов края, обладающего уникальными природными условиями, определенными его географией (расположение вдоль побережья Каспийского моря, наличие равнинной зоны, степей, предгорий и гор Большого Кавказа), можно было наблюдать и в рассматриваемый в нашем исследовании период. В то же время в этой области своей жизнедеятельности дагестанцы стали испытывать совершенно новые, непривычные для них веяния, часть которых никак не могла обрести благодатную почву, а часть со временем была воспринята местным населением и стала нормами нового образа жизни.

В январе 1930 г. в кинотеатре г. Махачкалы была предпринята попытка демонстрации художественно-пропагандистской кинокартины «Путь к здоровью и красоте» [21]. Создатели фильма, снятого в Германии в 1925 г. и больше известного под названием «Путь к силе и красоте» [1], преследовали практическую цель - привить немецкой молодежи интерес к культуре тела, здоровому образу жизни. По мнению критиков кинолента давала наглядное представление о путях физического оздоровления нации.

Сомнительно, что жителей республики, большинство населения которой исповедовало ислам, могла увлечь кинолента, в которой при выполнении физических упражнений демонстрировались полуобнаженные, пусть и источающие здоровье и силу, мужские и женские тела. Поскольку объявление о сеансе картины было напечатано в газете лишь единожды - 22 января 1930 г. - мы предполагаем, что фильм с проката сняли, поскольку организаторами показа не был учтен дагестанский менталитет. Но даже в самом факте неудавшейся демонстрации киноленты просматривалась наметившаяся по стране тенденция, отразившая стремление властных структур ориентировать граждан на усиленную физическую подготовку в условиях нарастающей напряженности международной обстановки: уже в 1931 г. Япония вторгается в Маньчжурию, нависает угроза ее дальнейшей агрессии на советский Дальний Восток, а в 1933 г. к власти в Германии приходит Адольф Гитлер, что усиливает вероятность развязывания войны на западе, в Европе.

Внутри страны ее руководство тем временем решало немало важных задач по укреплению государства и воспитанию граждан в духе созидателей и 
надежных защитников советского строя. В 1930-е гг. перед государством, так же как и в первое десятилетие советской власти, стояла задача формирования «нового» человека в условиях новой бытовой культуры. Все более прочные позиции стали занимать физкультура и спорт, которые превращались в важный элемент организованного досуга советского человека. Их массовое распространение должно было послужить не только делу укрепления здоровья граждан, но и борьбе с негативными бытовыми явлениями, формированию готовности совершать трудовые или военные подвиги во славу своей страны и противостоять внешнему и внутреннему врагу. По сути, массовая физкультура провозглашалась средством классовой борьбы [47, с. 541]. Развитие физической культуры и спорта отражало процесс складывания новых социальных связей в обществе.

В 1920-е гг. управление спортивной деятельностью на местах находилось в ведении профсоюзов. Общее руководство спортом осуществлял Высший совет физической культуры (ВСФК). В Дагестанской АССР Совет по физической культуре был создан по решению ДагЦИК 16 июля 1924 г. Когда потребовалось усиление централизации во всех областях государственного управления, в том числе в сфере физкультуры и спорта, ВСФК при ВЦИК РСФСР был реорганизован в ВСФК при ЦИК СССР (1930 г.), а в 1936 г. - во Всесоюзный комитет по делам физической культуры и спорта СНК ССCР, что еще более усилило контролирующие функции органа [47, с. 542].

Еще в 1918 г. уроки физкультуры стали обязательными в школьной программе. На протяжении 1920-х гг. сохранялась и обязательность занятий физкультурой в рамках допризывной подготовки. В 1930-е гг. увлечение населения занятиями физической культурой начинает приобретать всеобщий характер, во многом благодаря разрешению игровых видов спорта и поощрению спортивных достижений. Уже к середине 1930-х гг. для мальчиков и юношей Советского Союза образцом культурного поведения становится милитаризованная модель [7, с. 64], что в свою очередь потребовало от них овладения военно-оборонными навыками и совершенствования физической формы.

В начале 1920-х гг. были распущены старые спортивные общества, лиги, союзы, созданы новые физкультурные организации, продолжали развиваться существовавшие спортивные организации трудящейся молодежи. В Дагестане первые физкультурные кружки и коллективы появились на фабрике им. III Интернационала, в порту и на железной дороге, активизировала работу футбольная лига, с мая 1927 г. заработало спортивное общество «Динамо», а в 1928 г. в столице республики г. Махачкале был открыт стадион «Динамо». В жизни дагестанцев возникло новое явление - массовые спортивные мероприятия. В ноябре 1927 г. в республике прошла Вседагестанская спартакиада, в которой приняли участие команды городов республики - Махачкалы, Дербента и Кизляра. Сельские спортсмены в спартакиаде не участвовали. Постепенно секции по разным видам спорта стали открываться не только в городах, но и в сельской местности. С 1931 г. основной формой организации физкультурной работы на селе стал колхозный кружок физкультуры. Постепенно в физкультурное движение наряду с юношами стали вовлекаться и девушки. Правда, их было немного, поскольку сохранявшиеся традиции сдерживали даже само желание женщин заниматься физкультурой и спортом.

К концу 1920-х гг. в республике насчитывалось 27 кружков по физической культуре, в том числе 21 профсоюзный кружок, занятия которых посещало 1112 человек, в том числе 397 женщин, а также 5 школьных кружков, в 
которыхзанимался 351 участник[42, Л.60]. В 1930-е гг. участие дагестанцев в физкультуре и спорте, в том числе женщин, заметно выросло. В 1934 г. в республике физкультурой и спортом занималось 4000 человек, а в 1936 г. - 25 000, в том числе более 5 тыс. девушек-горянок. В этот год в Дагестане работало 62 спортплощадки, 3 спортклуба и 12 залов, а дагестанские горянки впервые начали играть в волейбол и даже вышли в полуфинал общесоюзных соревнований [23, c. 520].

В 1930-е гг. как во всей стране, так и в северокавказском регионе и в республике продолжала разворачиваться кампания агитации за спорт и здоровый образ жизни. Это находило выражение в организации массовых шествий физкультурников, спортивных праздников, в наглядной агитации и т.д. Подобные мероприятия становились атрибутом новой жизни. По сути превращаясь в спортивно-театральные постановки, они производили сильное впечатление как на их участников, так и на зрителей.

С 1 по 5 сентября 1932 г. в г. Нальчике прошла Северокавказская краевая спартакиада [32, с. 4], в которой приняли участие 600 физкульту рников из Адыгеи, Карачая, Черкесии, Северной Осетии, Ингушетии, Чечни, Дагестана, Кабардино-Балкарии, а также национальных частей Северокавказского военного округа [3, с. 128]. Спортивный коллектив Дагестана на спартакиаде был представлен 38 мужчинами и 8 женщинами из народностей республики. По итогам соревнований команда Дагестана заняла второе место общекомандного первенства и получила приз Крайсовпрофа - статуэтку «Красный партизан».

Дагестанские спортсмены завоевали первое место в соревнованиях по пятиборью комплекса «Готов к труду и обороне) и получили знамя в качестве приза Краевого совета физкультуры, за второе место в национальной борьбе они были премированы статуэткой «Боксеры». В стрелковом комплексе дагестанцы заняли первое место в стрельбе из боевых и мелкокалиберных винтовок, в толкании камня-третье, а в военизированном переходе - четвертое. В конкурсе национальных танцев они разделили второе место с участниками соревнований из Чеченской области, уступив первое место представителям Кабардино-Балкарии, а по эстафетному бегу заняли первое место, по футболу и волейболу (и среди мужских, и среди женских команд) - второе. Из дагестанских спортсменов-мужчин особо отличились Мурзаев - в соревнованиях по пятиборью, в забеге на 100 метров, метании диска, М. Гамзатов - в пятиборье, метании гранаты, Хафаров (Ханмурзаев) - в пятиборье, прыжках в длину, Ахмедов - в пятиборье, беге на 100 метров, Дотоев - в толкании камня, национальной борьбе, Курбанов - в метании диска, Мурилов - в национальной борьбе, Юсупов - в национальных танцах. Из девушек успешно выступили Гасанова (первое место по стрельбе из боевых и мелкокалиберных винтовок), Магомедова (первое место в беге на 60, 100 и 500 метров, в прыжках в длину с разбега и второе место в пятиборье), Хусаинова (второе место в прыжках в длину с разбега), Зайналбекова (четвертая в прыжках в длину с разбега и пятая в пятиборье) $[32$, с. 4].

12-13 октября 1934 г. в Махачкале на стадионе «Динамо» проходила третья спартакиада народов Дагестана. В ее программу были включены соревнования по бегу, метанию копья и меча, метанию диска и гранаты, толканию ядра, футболу, волейболу, городкам, по прыжкам в высоту и прыжкам с шестом, по национальным танцам и перетягиванию каната $[13$, с. 1].

В спартакиаде состязалось 1125 молодых людей из Москвы, Баку, Ленинграда и, конечно же, из Дагестана [41, с. 3]. Они представляли профсоюзы, РККА (Рабоче-крестьянская Красная армия), 
Осоавиахим (Общество содействия обороне авиации и химическому строительству), сельскохозяйственный институт, медтехникум, школьные коллективы. Спортсмены приняли участие в праздничной церемонии открытия спартакиады на стадионе «Динамо». С трибуны их приветствовали руководители республики - представители Дагобкома ВКП(б), ДагЦИКа, ДК ВЛКСМ, ДСПС (Дагестанский совет профессиональных союзов), что тоже стало обязательным атрибутом подобных мероприятий. С восторгом зрители встретили колонну физкультурников из Гунибского района. Возглавлял ее знаменосец, воплотивший в себе маскулинный образ дагестанского юноши-спортсмена, 22-летний Осман Абдурахманов, прозванный «дагестанским Гулливером». Абдурахманов должен был продемонстрировать свое умение в метании камня и технике метания собирался обучаться у чемпиона Советского Союза по метанию копья Я. Томма $[39$, с. 4]. Осман Абдурахманов стал победителем соревнований, метнув восьмикилограммовый камень на 10 метров 15 сантиметров $[10$, c. 4], а во время показательных соревнований в перетягивании каната одолел двух молодых «силачей» [33, с. 4]. У себя в ауле Осман, который ростом и статью пошел в мать, снискал славу самого сильного среди местных мужчин. Побывав на спартакиаде, юноша ощутил большое желание заниматься спортом. Ему нравилось поднимать тяжести, заниматься боксом, но больше всего тянуло к борьбе. В декабре 1934 г. Осман отправился в Москву, где приступил к тренировкам в Центральной тяжелоатлетической школе МСПС (Московский совет профессиональных союзов) под руководством неоднократного чемпиона СССР. по борьбе Катулина [31, с. 4]. К слову, в эти же годы известным в республике мастером по метанию камня стал юноша из с. Урахи Сергокалинского района Али Исаев, который в 1935 г. на спартакиаде народов
Северного Кавказа установил новый рекорд края. В 1937 г. А. Исаев стал слушателем Высшей школы тренеров в Москве

Девушки в ходе третьей спартакиады народов Дагестана соревновались в женском индивидуальном беге на 60 метров. Дагестанка из спортивного общества «Динамо» Измаилова заняла третье место после Стрижневой из г. Москвы и Демидовой из г. Баку. Для девушек были организованы соревнования в женской эстафете 4 по 100 метров, по волейболу, городкам, прыжкам, метанию мяча и диска. Измаилова в соревнованиях по прыжкам в длину с места среди девушек показала результат 4,75 метра [14, с. 4].

Патимат Гайдарова, учительница из c. Чох Гунибского района Дагестанской $\mathrm{ACCP}$, получившая среди своих земляков известность как искусная исполнительница национальных танцев, активно занималась физкультурой, сдала норму на значок «Ворошиловский стрелок». На спартакиаду она приехала поучаствовать не только в танцевальных состязаниях, но и в беге, прыжках и метании диска. Воодушевленная атмосферой спартакиады, Патимат взяла на себя обязательство обучить лезгинке трех девушек из своего села, грамоте двух женщин-горянок, а девушек-односельчанок вовлечь в избирательную кампанию $[11$, с. 4$]$.

Итак, на примере участия девушек, наряду с мужчинами, в массовых физкультурно-спортивных мероприятиях мы видим, что происходили изменения в охраняемом дагестанским обществом гендерном порядке, трансформировались гендерные стереотипы для женщин. Девушки-горянки не только стали присутствовать в общественных местах - на стадионах, в спортивных залах, тирах и т.Д., но и проявлять невиданную ранее публичную физическую активность. Участницы соревнований для удобства переходили на более свободный стиль одежды. Сильным, независимым, спортивным теперь выглядел не только мужчина, но и 
женщина. В этом и состоял сдвиг гендерных стереотипных норм в обществе по принципу «слабого» и «сильного» пола. В то же время не могли не сохраниться и определенные гендерные стандарты. Мужчины были представлены в силовых видах спорта - метание камня, борьба, перетягивание каната и др., а женщины соревновались исключительно в женских состязаниях - в беге, прыжках, метании диска, волейболе, национальных танцах, городках, стрельбе.

Сохранению гендерных стандартов способствовали действия традиционно и консервативно настроенных слоев населения. К примеру, в с. Гуниб Гунибского района республики молодые горянки организовались в волейбольную команду, но она быстро распалась. Как оказалось, горянок стали высмеивать свои же сельчане. Разия Нахибашева рассказывала: «Нас окружает заедающая обстановка. Нас заставляют стесняться выходить на площадку. Разбирают нас и по ногам, и по телосложению, когда выходим на площадку для физкультурных занятий» $[44$, c. 3].

В 1930-е гг. в республике функционировали спортивные общества «Динамо», «Локомотив», «Водник», «Учитель», «Медик», «Буревестник», «Строитель» и др. Если в 1920-е гг. формирование спортивных обществ шло, как правило, по территориальному принципу, то в середине 1930 -х гг. стали организовываться ведомственные спортивные общества. Теперь государственным структурам легче было оказывать им помощь и контролировать их работу. Именно в этих организациях зарождался спорт высших достижений. Физкультура и спорт обрели новую организационную структуру и стали развиваться более динамично и целенаправленно. Они становились более массовыми, вовлекали в свои ряды учащихся учебных заведений, молодежь, занятую на производстве, и, конечно же, девушек-горянок.
Начиная с середины 1930-х гг. массовый характер приобретает альпинизм. В апреле 1935 г. состоялось первое в СССР восхождение на гору Казбек в зимних условиях жен командного состава Красной армии $[48$, с. 4]. Группой женщин руководил Н.Ф. Ватутин $[3$, с. 139], ставший видным военачальником в годы Великой Отечественной войны. А в 1935 г. Н.Ф. Ватутин являлся начальником штаба 28-й горной стрелковой дивизии (г. Орджоникидзе, ныне г. Владикавказ). В восхождении приняли участие супруги командиров красноармейского полка, дислоцированного в г. Буйнакске, К. Мамина и Л. Грачева, командиром похода была А. Леухина из г. Орджоникидзе. Конкуренцию «армейским женам» составили 10 ростовских комсомолок, узнавших о восхождении из газет. Жены командиров взяли на себя обязательство дойти до цели в полном составе [48, с. 4]. Ранее из восьми мужчин полка на вершину Казбека добралось пятеро. Женщинам повезло больше: они выполнили обязательство. Альпинистки вспоминали о чувстве радости, охватившем их на вершине горы и слившемся с необъятным чувством гордости за всю страну.

После возвращения в Дагестан K. Мамина развернула спортивно-массовую работу среди горянок: организовала поход Буйнакск - Махачкала, а также военизированный поход Буйнакск - Грозный. В последнем походе приняло участие 11 горянок и 10 жен командиров Н-ской части (так в источнике - прим. авт.) [3, с. 139]. С каждым годом альпинизм набирал в Дагестане всё большую популярность. В 1937 г. дагестанские альпинисты совершили восхождение на горы Эльбрус, Аддала (третья по высоте горная вершина в Дагестане, зачетная на Значок альпиниста первой ступени), Казбек и ставили вопрос об открытии у подножия горы Аддала сезонного лагеря альпинистов на 50 человек $[12$, с. 4]. 
В марте 1936 г. спортсмены Махачкалы, наряду со спортсменами из Орджоникидзе, Грозного и Пятигорска, участвовали в краевых соревнованиях по тяжелой атлетике. В итоге махачкалинцы поделили 2-е и 3-е места со спортсменами из г. Грозный [3, с. 133]. А с 30 августа по 1 сентября 1936 г. в Пятигорске проходила краевая спартакиада горянок. Дагестанские девушки по итогам прошедших соревнований заняли третье место.

В постановлении СНК ДАССР о работе Республиканского комитета по делам физической культуры и спорта (январь 1938 г.) предлагалось усилить физкультурную и массово-спортивную работу в районах, улучшить физическое воспитание в школах, повысить врачебный контроль над занятиями физкультурников [29, с. 1]. Результативность подобных решений органов власти подтверждалась на практике. В феврале 1938 г. в высокогорном Тляратинском районе в колхозах им. К. Маркса, им. Микояна и др. были организованы хоровые, танцевальные и физкультурные кружки. Впервые девушки-горянки надели спортивные костюмы и стали выходить на занятия вместе с мужчинами в большой зал клуба колхоза им. Микояна. Девушки занимались вольными упражнениями, спортивными играми под руководством физкультурного работника. 18 горянок-комсомолок с. Укал (Тляратинский район) сдали нормы на значок «Ворошиловский стрелок». Горянки, среди которых были Хадижат Улуханова, Патимат Гаджиева, Ашура Магомедова, Муслимат Курбанова, Хабибат Гусейнова, Бика Хаджимуратова и др., стреляли метко, без промаха. В этом же селе еще 50 представителей молодежи готовились сдать нормы на значок «Ворошиловский стрелок», в том числе 25 горянок.

18 января 1938 г. 15 девушек из с. Кутлаб совершили пеший переход по маршруту: Кутлаб - Укал - Чадаклоб Тлядал - Бежета - Кутлаб. Горянки шли по труднодоступным горным тропам, засыпанным снегом, проверяли готовность колхозов к окотной кампании овец, помогали колхозникам, чем могли. И хотя столь непривычные для сельской горной местности начинания сопровождали слухи и сплетни, девушек это не останавливало [8, с. 4]. Другая группа девушек-горянок совершила переход по селам Саниорта и Хадияв, посвятив его 20 -й годовщине Красной армии и флота. По словам секретаря Тляратинского райкома ВКП (б), во всех селах района были организованы кружки ворошиловских кавалеристов и стрелков. Горцы и горянки ежедневно упражнялись в стрельбе и верховой езде, чтобы на празднике продемонстрировать свое умение метко стрелять и лихо джигитовать на лошади. В районе при радиоузле был организован кружок по изучению мотора и управлению машиной. Для проведения практических занятий руководство района приобрело мотоцикл, чтобы девушки могли обучаться самостоятельному вождению $[9$, c. 4].

С 7 по 27 августа 1938 г. ЦК Профсоюза работников начальной и средней школы и Центральным советом спортивного общества «Учитель» был организован женский велопробег, посвященный 20-летию ВЛКСМ и подготовке школ к новому учебному году. Маршрут протяженностью 1500 км пролегал через Москву - Великие Луки - Новгород Калинин - Москву. В велопробеге участвовала дагестанка, уроженка с. Дучи Лакского района, студентка Дагестанского педагогического института Т. Сулейманова [35, с. 4].

На 18-20 августа 1938 г. в Махачкале было запланировано проведение второй дагестанской спартакиады женской молодежи. Она была посвящена 20-летию ВЛКСМ, свидетельствовала о разворачивающейся среди дагестанской молодежи массовой физкультурной работе и должна была отразить спортивно-технические 
достижения девушек-горянок в области физкультуры и спорта. Республиканская спартакиада прошла после проведения городских и районных спартакиад.

Соревнования проводились по двум группам. В одной из групп состязались коллективы городов Махачкала, Дербент, Буйнакск, Хасавюрт и поселка Двигательстрой (ныне г. Каспийск). Во второй группе - коллективы из районов республики. От Махачкалы в спартакиаде принимали участие коллективы «Динамо», «Спартак» и добровольные спортивные общества профсоюзов. Команды разыгрывали личное первенство по легкой атлетике (бег на 100 м и 500 м, прыжки в длину и высоту с разбега), метанию гранаты, стрельбе, волейболу. Для городских команд добавлялись соревнования по баскетболу.

К соревнованиям не допускались участницы моложе 16 лет, в городских командах должно было быть по 10 участниц и одному представителю, в районных - по 6 участниц и одному представителю. Определенные требования были и к форме соревнующихся (например, цвета майки и трусов и т.д.). Проезд участниц оплачивался командирующей организацией, а проживание и питание - Дагестанским комитетом по делам физкультуры и спорта при СНК ДАССР [34, л. 22, 22 об., 23].

В подобные соревнования втягивались девушки по всей стране. Документальные свидетельства говорят о том, что юбки, в которых они поначалу посещали физкультурные занятия, сменила спортивная форма. По распоряжению Н.И. Подвойского, летом на тренировки и состязания юноши должны были приходить в трусах, а девушки - в трусах и легких блузах, и тем самым пропагандировать более здоровое, правильное отношение к человеческому телу [28, с. 36]. По сведениям исследователя М.И. Мирошниченко, на Урале в начале 1920-х гг. для спортивных занятий для женщин закупались специальные дамские костюмы и рубашки, дамские шаровары, «дамские туфли с гвоздями» или «дамские туфли без гвоздей» [28, с. 36]. Интересно, что в документальных источниках, оказавшихся в нашем распоряжении, мы подобных свидетельств не обнаружили.

В сентябре 1938 г. на стадионе «Динамо» была проведена Дагестанская спартакиада, посвященная 20-летию ВЛКСМ. Из девушек в ходе соревнований отличились: в личном первенстве Габиева (Кулинский район); в забеге на 100 метров Крючкова («Динамо») и Аджигитова («Медик»); в толкании ядра Большакова («Двигательстрой»), Яковлева и Саввина («Пищевик») [15, с. 4]; в прыжках в длину с разбега Османова Джарадат (Ботлихский район), Шамсуева Хабизат (Хунзахский район) $[26$, с. 4] и др. 28 сентября Комитет по делам физкультуры и спорта премировал 8 лучших участников спартакиады - горцев и горянок победителей соревнований. К примеру, Джамалутдин Гасанов, бывший колхозник-стахановец колхоза им. Евдокимова (с. Кудали Гунибского района) был выдвинут на должность районного уполномоченного по физкультуре и спорту и премирован велосипедом. Меджидов Магомед, кассир Гунибской сберкассы, был премирован фотоаппаратом, Османова Джарадат - велосипедом и т.д. [25, с. 4].

Большую роль в развитии физкультурной работы в стране сыграл комплекс «Готов к труду и обороне» (ГТО), созданный по инициативе ВЛКСМ. В 1931 г. была введена в действие первая ступень, в 1932 г. - вторая, а в 1934 г. - комплекс для юношества «Будь готов к труду и обороне) (БГТО). Складывалась практическая основа советской системы физического воспитания. Комплекс учитывал возраст и пол занимающихся, включал в себя нормативные показатели и обеспечивал физическую, трудовую и военную подготовку юношей, девушек (с 1934 г. мальчиков и девочек) и взрослого населения. В 1939 г. был создан новый комплекс 
«Готов к труду и обороне СССР», который имел два раздела: общие нормы и требования, обязательные для всех сдающих, и нормы по выбору. Таким образом, была проведена большая и последовательная работа по внедрению массовых физических упражнений с военным уклоном. В стране развернулось обучение молодежи не только физической подготовке, но и стрелковому, парашютному, авиационному, автомобильному, конному, военнохимическому, военно-санитарному делу, знанию топографии. К концу 1930-х гг. оборонное дело становится основным лейтмотивом советского спорта.

Подготовка дагестанской молодежи к сдаче норм ГТО имела важное значение. Достаточно сказать, что в 1931 г. в организованных физкультурных коллективах систематической физкультурной работой было охвачено только 1-2\% населения [5, c. 31], а свидетельством успешного выполнения работы по введению комплекса ГТО в Дагестане стал следующий показатель: за 1939 г. в республике было подготовлено 3900 значкистов ГТО вместо запланированных 2330 [5, с. 34]. K сожалению, мы пока не располагаем релевантными статистическими данными, позволяющими нам сделать обоснованные и репрезентативные выводы о количественных характеристиках участия дагестанских женщин в физкультурных и спортивных мероприятиях и сдаче норм ГТО, но убедительно можем говорить об их устойчивом численном росте.

Физкультура, спорт и комплекс ГТО получали все большее признание среди детей и молодежи. Ф.А. Агапов и М.-Ш. Ахмедов считают, что именно комплекс ГТО существенно помог дагестанской девушке-горянке включиться в физкультурное движение в республике [5, с. 33]. Важное значение приобрела оборонно-спортивная подготовка. Ставилась задача максимального охвата обороннофизкультурными кружками, подготовки значкистов ВС (Ворошиловский стрелок),
ПВХО (Противовоздушная и химическая оборона), ГТО и БГТО (Готов к труду и обороне, Будь готов к труду и обороне), ГСО (Готов к санитарной обороне) и др. В эту работу активно включились партийные, комсомольские и профсоюзные организации, педагоги.

В конце 1930-х гг. государство стало выделять всё больше средств на организацию оборонной работы. И если сначала она проводилась в основном в городах, то со временем серьезное внимание этой работе стало уделяться и в сельской местности.

Патриотическое воспитание и оборонно-массовая подготовка молодежи стали задачей многих общественных организаций. Созданное еще в 1927 г. Общество содействия обороне, авиационному и химическому строительству (Осоавиахим) должно было активно содействовать подготовке резервов для армии и флота. В конце 1930-х гг. эта общественно-политическая оборонная организация, по существу, превратилась в военизированную.

В заключение хотелось бы привести еще один яркий пример вовлечения дагестанской молодежи, а точнее девушек-горянок, в военно-спортивную работу. Речь пойдет о первой летчице-дагестанке.

Осенью 1933 г. в республике проводился месячник авиации, во время которого дагестанцы собрали средства на покупку двух самолетов. Было решено организовать авиамодельные кружки в школах, планерные кружки на крупных предприятиях, в совхозах и МТC, а также открыть аэроклуб в Махачкале. В задачи аэроклуба входила организация агитационной, пропагандистской, общественной, политической, массовой работы, подготовка планеристов, летчиков, парашютистов, техников, мотористов, радистов, метеорологов, фотомастеров, а также проведение научно-исследовательской и конструкторской работы.

В первой летной группе аэроклуба, состоявшей из юношей и девушек, 
проходила обучение полетам на учебном самолете У-2 уроженка с. Чуртах Лакского района республики, комсомолка-выдвиженка 19-летняя Бавер Джафарова. Она была самой юной из членов группы. Бавер, дочь участника Гражданской войны и председателя местного колхоза, единственная девушка из села, поехавшая учиться в город. Для горного аула по тем временам - случай неординарный: это трудно было понять местным жителям, с трудом принимавшим политику советской власти в женском вопросе. О Бавер по селу и району поползли нелицеприятные слухи. Встревоженные родители потребовали, чтобы девушка вернулась домой. Она подчинилась, оставив учебу. В ауле Бавер организовала комсомольскую ячейку, создала пункт по ликвидации неграмотности, стала вести занятия и вовлекать в учебу девушек-горянок. Но юная активистка продолжала мечтать о завершении образования и возможности научиться летать. Ее мечте было суждено сбыться, когда в Махачкале открылся аэроклуб [30, с. 3].

Это сегодня авиационный спорт считается гендерно-нейтральным [16, с. 264], а во второе десятилетие советской власти традиционному дагестанскому обществу всё еще трудно было принять девушек в профессии учителя и врача, не говоря уже о профессии летчицы. Но реальность оказалась сильнее. И вот Бавер Джафарова не только поднимается в небо, но и работает ответственным инструктором в ДагЦИКе, подтянутая и уверенная, в гимнастерке, с непривычной для дагестанок короткой стрижкой, в сентябре 1935 г. председательствует на Первом вседагестанском съезде женской молодежи. Накануне съезда для его делегатов был организован авиационный праздник. Три самолета, за штурвалом одного из которых находилась Джафарова, демонстрировали фигуры высшего пилотажа [36, с. 4]. После выступлений девушкам предложили полетать на самолетах. Горянки были переполнены впечатлениями: ведь многие из них не то что не летали, но и за свою жизнь ни разу не видели воздушных машин. Некоторые девушки изъявили желание последовать примеру первой дагестанской летчицы.

Итак, физическая культура и военно-оборонная работа стали интенсивнее входить в жизнь дагестанцев. В городах и селах, в том числе в горных, создавались новые физкультурные организации, добровольные общества, в них вливались всё более широкие слои населения Дагестана. В предвоенные годы приоритетное внимание стало уделяться вовлечению в физкультурное и военно-спортивное движение девушек-дагестанок. Более заметным их участие было в близких к традиционным спортивно-ориентированным видам досуга дагестанцев.

Физкультурное и военно-спортивное движение стало одним из пунктов программы решения «женского вопроса). Несмотря на консервативность воспитательных традиций, традиционный бытовой уклад дагестанцев, в жизни утверждались преобразования, направленные на изменение женского статуса, внешняя сторона которого проявлялась в перемене манеры поведения, одежды и т.д. Этому во многом способствовало активное привлечение женщины, девушек-горянок к физкультурно-спортивной работе, участию в самых разных соревнованиях, усвоению ими новых поведенческих стереотипов, норм общения, моральнонравственных принципов, что создавало условия для конструирования нового женского образа в контексте более прогрессивного социалистического образа жизни. К физкультурным и спортивным мероприятиям в первую очередь должны были активно привлекаться работницы и колхозницы, но на деле большинство среди их участниц составляли служащие, учащиеся, студентки.

Проведение физкультурных и спортивных мероприятий в форме массовых 
праздников создавало торжественную и привлекательную атмосферу, еще непривычную для большинства горянок, символизируя реалии нового советского образа жизни. Оно отражало состояние широкомасштабной агитационно-пропагандистской работы и патриотического воспитания, способствовало вовлечению женщин в дальнейшую общественную и политическую деятельность, создавало условия для отвлечения горянок от патриархальной семьи.

Во многих горных селах девушкигорянки впервые надели спортивные костюмы, начали заниматься в физкультурных кружках, активно записываться в волейбольные команды, участвовать в работе военных кружков, соревнованиях по сдаче норм ГТО, на значки «Ворошиловский стрелок» и т.д. Эффективность проводимой среди дагестанских девушек и юношей работы во многом обеспечивалась деятельностью Осоавиахима, спортивных обществ, общественных организаций, военных специалистов из рядов Рабоче-крестьянской Красной армии (РККА), а также комсомола. Большой популярностью у подростков, молодежи, учителей Дагестана, как, впрочем, и других районов северокавказского региона [24; 38, с. 198], пользовались такие виды оборонно-спортивного движения, как стрелковое дело, авиационное дело, спортивный альпинизм, велопробеги и мотопробеги, конные и пешие военизированные походы и др. Участие женщингорянок в физкультурном и спортивном движении возрастало прямо пропорционально развертыванию оборонного движения, отвечающего задачам укрепления обороноспособности страны в условиях нарастающей военной угрозы.

\section{ЛИТЕРАТУРА:}

1. Путь к силе и красоте. Wege zu Kraft und Schonheit. Ein Film uber moderne Korperkultur». [Электронный pecypc]. URL: https://www.kinopoisk.ru/film/39419/ (дата обрашения 10.01.2020)

2. Агапов Ф.А. Очерки развития физической культуры в Дагестане. Махачкала: Дагучпедгиз, $1966.98 \mathrm{c}$.

3. Агапов Ф.А. Физическая культура и спорт у горских народов Северного Кавказа. Махачкала: Дагучпедгиз, 1971. 235 c.

4. Агапов Ф.А. Эстафета сильных и смелых: очерк развития физкультуры и спорта в Северной Осетии за годы советской власти. Орджоникидзе: Северо-Осетинское книжное издво, $1964.110 \mathrm{c}$.

5. Агапов Ф.А., Ахмедов М.-Ш. ГТО на службе здоровья. Махачкала: Дагестанское книжное изд-во, 1975. $56 \mathrm{c}$.

6. Ахмедов М.-Ш. Знаменосцы дагестанского спорта. Махачкала Дагестанское книжное изд-во, 1972. 144 с.

7. Бернстейн С. Воспитанные при Сталине: комсомольцы и защита социализма / Сет Бернстейн; пер. с англ. Л.Е. Сидиковой. М.: РОССПЭН, 2018. 64 с.

8. Бижанов А. Горянки-физкультурницы // Дагестанская правда. 1938. 6 февр.

9. Бижанов А. Горянки овладевают винтовкой и мотоциклом // Дагестанская правда. 1938 12 февр.

10. Вин С. Демонстрация высокой техники спорта // Дагестанская правда. 1934. 17 окт.

11. Гайдарова П. Мои обязательства // Дагестанская правда. 1934. 18 окт.

12. Горный спорт // Дагестанская правда. 1938. 29 марта.

13. Дагестанская правда. 1934. 12 окт.

14. Дагестанская правда. 1934. 15 окт.

15. Дагестанская спартакиада. Второй день // Дагестанская правда. 1938. 27 сент. 
16. Иванова И.Б., Самойлова Е.Г. Гендерные особенности в структуре физической культуры и спорта [Электронный ресурс] // Социально-гуманитарные знания. 2017. № 12. С. 258-264. URL: https://cyberleninka.ru/article/n/gendernye-osobennosti-v-strukture-fizicheskoy-kultury-isporta (дата обращения 20.07.2021).

17. Иерусалимская С.Ю., Иерусалимский Ю.Ю. Методы исследования в отечественной исторической науке конца XX - начала XXI в. // Известия Самарского научного центра Российской академии наук. 2018. Т. 20, № 3 (2). С. 395-398.

18. Кабирова А.Ш. Организация физкультурно-массовой работы в Татарской АССР в предвоенные годы и в период Великой Отечественной войны [Электронный ресурс] // Вестник Оренбургского государственного педагогического университета. 2020. № 2 (34). С. 141-153. / URL: https://elibrary.ru/download/elibrary_43080078_18394601.pdf (дата обращения 20.07.2021).

19. Каймаразов Г.Ш. Культурное строительство в автономных республиках Северного Кавказа. 1920-1960 гг. История. Проблемы взаимодействия. Ч. 1. Махачкала: Алеф, 2016. 216 с.

20. Каймаразов Г.Ш. Очерки истории культуры народов Дагестана. От времени присоединения к России до наших дней. М.: Наука, 1971. 410 с.

21. Кино-Шарк. Новейший фильм физической культуры. Путь к здоровью и красоте: в 6-ти частях. Научная проработка доктора Кауфмана // Красный Дагестан. 1930. 22 янв.

22. Кулинич Н.Г. Физическая культура в жизни горожан советского Дальнего Востока в 1920-1930-е гг. [Электронный ресурс] // Вестник Томского государственного университета. 2011. № 1 (20). C. 267-272. URL: https://elibrary.ru/download/elibrary_16208427_31454598.pdf (дата обращения 20.07.2021).

23. Культурное строительство в Дагестанской АССР (1918-1941 гг.): сборник документов. T. I. Махачкала: Дагестанское государственное книжное издательство, 1980.768 с.

24. Ладыгин С.В. Военно-патриотическое воспитание молодежи Карачая и Черкесии накануне Великой Отечественной войны // Научные проблемы гуманитарных исследований. 2010. № 1. С. 71-76.

25. Лидин Е. Дагестанская спартакиада. Победители // Дагестанская правда. 1938. 29 сент.

26. Лидин Е. Дагестанская спартакиада. Третий день // Дагестанская правда. 1938. 28 сент.

27. Мирошниченко М.И. «Старому быту гроб, даешь физкультуру и спорт!»: физкультурницы и спортсменки Урала во второй половине 1920-х гг. // Исторические, философские, политические и юридические науки, культурология и искусствоведение. Вопросы теории и практики. 2014. № 1 (39). С. 150-154.

28. Мирошниченко М.И. Женщины в физкультуре и спорте на Урале в первой половине 1920-х годов [Электронный ресурс] // Вестник Южно-Уральского государственного университета. 2012. № 32 (291). C. 36-40. URL: https://elibrary.ru/download/elibrary_17956132_98377816. pdf (дата обращения 20.07.2021).

29. О работе республиканского комитета по делам физической культуры и спорта: Постановление СНК ДАССР // Дагестанская правда. 1938. 22 янв.

30. Озимый. Летчик Джафарова Бавер // Дагестанская правда. 1935. 1 мая.

31. Осман Абдурахман // Дагестанская правда. 1935. 4 янв.

32. Пельш. Результаты участия Дагестана на Краевой национальной спартакиаде // Дагестанская правда. 1932. 30 сент.

33. Показательные выступления // Дагестанская правда. 1934. 18 окт.

34. О проведении Дагестанской спартакиады женской молодежи. 1938 г.: Постановление СНК ДАССР и Бюро Дагобкома ВКП (б) // Центральный государственный архив Республики Дагестан (ЦГА РД). Ф. 168-р. Оп. 18. Д. 99.

35. Пробег велосипедисток // Дагестанская правда. 1938. 21 авг.

36. Пронский А. Праздник на аэродроме // Дагестанская правда. 1935. 27 сент. 
37. Об утверждении Стратегии развития физической культуры и спорта в РФ на период до 2030 года [Электронный ресурс]: Распоряжение Правительства РФ от 24 ноября 2020 г. № 3081p. URL: https://www.garant.ru/products/ipo/prime/doc/74866492/ (дата обращения 09.07.2021).

38. Самбур Б.Н. Военно-патриотическая подготовка и трудовое использование подростковой молодежи накануне и в начале Великой Отечественной войны (на примере Ставропольского края) // Вестник Кемеровского государственного университета. 2015. № 2 (62). T. 6. C. $198-201$.

39. Сетим. Старый молодой. Мы покажем технику физкультуры // Дагестанская правда. 1934. 14 окт.

40. Соловьев П.В. Физкультурное движение в Томске в 1920-1930-х гг:: борьба за массовость [Электронный ресурс] // Вестник Томского государственного университета. 2007. № 300-3. C. 66-68. URL: https://elibrary.ru/download/elibrary_12224883_79264352.pdf (дата обращения 20.07.2021).

41. Спартакиада открыта // Дагестанская правда. 1934. 14 окт.

42. Статотчет о работе Дагсовета. 1929 г. // ЦГА РД. Ф. 187-р. Оп. 1. Д. 56.

43. Стряпихина А.А. Становление физкультурного движения и реализация комплекса ГТО в СССР // Исторические, философские, политические и юридические науки, культурология и искусствоведение. Вопросы теории и практики. 2015. № 4 (54). С. 164-167.

44. Сулейманов Х. Больше внимания работе среди девушек // Дагестанская правда. 1935. 8 сент.

45. О физической культуре и спорте в Российской Федерации [Электронный ресурc]: Федеральный закон от 4 декабря 2007 г. № 329-Ф3 (с изменениями и дополнениями). URL: https:// base.garant.ru/12157560/ (дата обращения 16.07.2021).

46. Хорошева А.В. «Великий перелом» в физкультуре: от самостоятельности к мобилизации народных масс // 1929: «Великий перелом» и его последствия: материалы XII Международной научной конференции (Екатеринбург, 26-28 сент. 2019 г.). М.: Полит. энциклопедия; Президентский центр Б.Н. Ельцина, 2020. С. 798-808.

47. Хорошева А.В. Физическая культура в советской повседневности в 1920-1930-е годы // Культура и власть в СССР. 1920-1930-е годы: материалы IX Международной научной конференции (Санкт-Петербург, 24-26 окт. 2016 г.). М.: Пол. энциклопедия, 2017. С. 541-550.

48. Швачко В. Смелые альпинистки // Дагестанская правда. 1935. 22 апр.

\section{REFERENCES:}

1. The way to strength and beauty. Wege zu Kraft und Schonheit. Ein Film über moderne Korperkultur [Electronic resource]. URL: https://www.kinopoisk.ru/film/39419/ (date of access 10/01/2020).

2. Agapov F.A. Essays on the development of physical culture in Dagestan. Makhachkala: Daguchpedgiz, 1966. 98 p.

3. Agapov F.A. Physical culture and sports among the mountain peoples of the North Caucasus. Makhachkala: Daguchpedgiz, 1971. 235 p.

4. Agapov F.A. Relay of the strong and brave (Essay on the development of physical culture and sports in the North Ossetia during the years of the Soviet power). Ordzhonikidze: the North Ossetian Book Publishing House, 1964. $110 \mathrm{p}$.

5. Agapov F.A., Akhmedov M.-Sh. GTO in the service of health. Makhachkala: Dagestan Book Publishing House, 1975. 56 p.

6. Akhmedov M.-Sh. Standard bearers of the Dagestan sports. Makhachkala Dagestan book publishing house, 1972. $144 \mathrm{p}$. 
7. Bernstein S. Brought up in the time of Stalin: Komsomol members and the defense of socialism / Seth Bernstein; transl. from English by L.E. Sidikova. Moscow: ROSSPEN, 2018. 64 p.

8. Bizhanov A. Mountain women-athletes // Dagestanskaya Pravda. 1938. Feb., 6.

9. Bizhanov A. Mountain women take possession of a rifle and a motorcycle // Dagestanskaya Pravda. 1938. 12 Feb.

10. Vin S. Demonstration of high sports technique // Dagestanskaya Pravda. 1934. Oct., 17.

11. Ghaydarova P. My obligations // Dagestanskaya Pravda. 1934.18 Oct.

12. Mountain sports // Dagestanskaya Pravda. 1938. March, 29.

13. The Dagestan truth. 1934. Oct., 12.

14. The Dagestan truth. 1934. Oct., 15.

15. The Dagestan Games. The Second day // Dagestanskaya Pravda. 1938. Sep., 27.

16. Ivanova I.B., Samoilova E.G. Gender characteristics in the structure of physical culture and sports [Electronic resource] // Social and humanitarian knowledge. 2017. No. 12. P. 258-264. URL: https://cyberleninka.ru/article/n'/gendernye-osobennosti-v-strukture-fizicheskoy-kultury-i-sporta (date of access 20. 07.2021).

17. Jerusalemskaya S.Yu., Jerusalemskiy Yu.Yu. Research methods in the Russian historical science at the end of the XX - beg. of the XXI century // Bulletin of the Samara Scientific Center of the Russian Academy of Sciences. 2018. Vol. 20, No. 3 (2). P. 395-398.

18. Kabirova A.Sh. Organization of mass physical culture activities in the Tatar ASSR in the pre-war years and during the Great Patriotic War [Electronic resource] // Bulletin of the Orenburg State Pedagogical University. 2020. No. 2 (34). P. 141-153. / URL: https://elibrary.ru/download/ elibrary_43080078_18394601.pdf (date of access 20.07.2021).

19. Kaymarazov G.Sh. Cultural construction in the autonomous republics of the North Caucasus. 1920-1960 History. Communication problems. Part 1. Makhachkala: Alef 2016. 216 p.

20. Kaymarazov G.Sh. Essays on the history of the culture of the peoples of Dagestan. From the time of joining Russia to the present day. M.: Nauka, 1971. 410 p.

21. Kino-Shark. The newest film of physical education. The path to health and beauty: in 6 parts. Scientific study of Dr. Kaufman // Red Dagestan. 1930. Jan., 22.

22. Kulinich N.G. Physical culture in the life of the townspeople of the Soviet Far East in the 1920s-1930s. [Electronic resource] // Bulletin of the Tomsk State University. 2011. No. 1 (20). P. 267272. URL: https://elibrary.ru/download/elibrary_16208427_31454598.pdf (date of access 20.07.2021).

23. Cultural construction in the Dagestan ASSR (1918-1941): a collection of documents. V. I. Makhachkala: Dagestan State Book Publishing House, 1980. 768 p.

24. Ladygin S.V. Military-patriotic education of the youth of Karachai and Circassia on the eve of the Great Patriotic War // Scientific problems of humanitarian research. 2010. No. 1. P. 71-76.

25. Lidin E. The Dagestan Games. Winners // Dagestanskaya Pravda. 1938. Sep., 29.

26. Lidin E. Dagestan Games. The third day // Dagestanskaya Pravda. 1938. Sep., 29.

27. Miroshnichenko M.I. "Old life goes into coffin, physical education and sports now!": Athletes and sportswomen of the Urals in the second half of the 1920s // Historical, philosophical, political and legal sciences, cultural studies and art history. Questions of theory and practice. 2014. No. 1 (39). P. $150-154$.

28. Miroshnichenko M.I. Women in physical culture and sports in the Urals in the first half of the 1920s [Electronic resource] // Bulletin of the South Ural State University. 2012. No. 32 (291). P. 3640. URL: https://elibrary.ru/download/elibrary_17956132_98377816.pdf (date of access 20.07.2021).

29. On the work of the republican committee for physical culture and sports: the solution of the Council of People's Commissars of the DASSR // Dagestan truth. 1938. Jan., 22.

30. Ozimiy. Pilot Jafarova Baver // Dagestanskaya Pravda. 1935. May, 1.

31. Osman Abdurakhman // Dagestan truth. 1935. Jan.,4. 
32. Pelsh. Results of Dagestan's participation in the Regional National Sports Games // Dagestanskaya Pravda. 1932. Sep., 30.

33. Demonstration performances //. Dagestanskaya Pravda. 1934.18 Oct.

34. About holding the Dagestan Spartakiad of female youth. 1938: the Resolution of the Council of People's Commissars of the DASSR and the Bureau of the Dagobkom of the CPSU (b) // Central State Archives of the Republic of Dagestan (CSA RD). F. 168-r. Op. 18. D. 99.

35. Cyclists' run //. Dagestanskaya Pravda. 1938. Aug., 21.

36. Pronsky A. Holiday at the airport // Dagestanskaya Pravda. 1935. Sep., 27.

37. On the approval of the Strategy for the development of physical culture and sports in the Russian Federation for the period up to 2030 [Electronic resource]: the Order of the Government of the Russian Federation of November 24, 2020 No. 3081-r. URL: https://www.garant.ru/products/ipo/ prime/doc/74866492/. (date of access 09/07/2021).

38. Sambur B.N. Military-patriotic training and labor use of adolescent youth on the eve and at the beginning of the Great Patriotic War (on the example of the Stavropol Territory) //. Bulletin of the Kemerovo State University. 2015. No. 2 (62). V. 6. P. 198-201.

39. Setim. Old young. We will show the technique of physical education // Dagestanskaya Pravda. 1934. Oct., 14.

40. Soloviev P.V. Physical culture movement in Tomsk in the 1920s-1930s: the struggle for mass [Electronic resource] // Bulletin of the Tomsk State University. 2007. No. 300-3. P. 66-68. URL: https://elibrary.ru/download///ibrary_12224883_79264352.pdf (date of access 20.07.2021).

41. The Spartakiad is open // Dagestanskaya Pravda. 1934. Oct., 14.

42. Statistical report on the work of the Dagsovet. 1929 // CSA RD. F. 187-r. Op. 1. D. 56.

43. Stryapikhina A. A. Formation of the physical culture movement and the implementation of the GTO complex in the USSR // Historical, philosophical, political and legal sciences, cultural studies and art history. Questions of theory and practice. 2015. No. 4 (54). P. 164-167.

44. Suleimanov H. More attention to work among girls // Dagestanskaya Pravda. 1935. Sep., 8.

45. On physical culture and sports in the Russian Federation [Electronic resource]: the Federal Law of December 4, 2007 No. 329-FL (with amendments and additions). URL: https://base.garant. $\mathrm{ru} / 12157560 /$ (date of access 16/07/2021).

46. Khorosheva A.V. "Great turning point" in physical education: from independence to mobilization of the masses // 1929: "Great turning point" and its consequences: materials of the XII International Scientific Conference (Yekaterinburg, September 26-28, 2019). M.: Polit. encyclopedia; B.N. Yeltsin, 2020. P. 798-808.

47. Khorosheva A.V. Physical culture in Soviet everyday life in the 1920s-1930s // Culture and Power in the USSR. 1920-1930s: Proceedings of the IX International Scientific Conference (St. Petersburg, October 24-26, 2016). M.: Great encyclopedia, 2017. P. 541-550.

48. Shvachko.V. Brave climbers // Dagestanskaya Pravda. 1935. Apr., 22. 